\title{
Technical note: Updated parameterization of the reactive uptake of glyoxal and methylglyoxal by atmospheric aerosols and cloud droplets
}

\author{
Leah A. Curry, William G. Tsui, and V. Faye McNeill \\ Department of Chemical Engineering, Columbia University, New York, NY 10027, USA \\ Correspondence: V. Faye McNeill (vfm2103@columbia.edu)
}

Received: 18 January 2018 - Discussion started: 22 January 2018

Revised: 19 June 2018 - Accepted: 29 June 2018 - Published: 12 July 2018

\begin{abstract}
We present updated recommendations for the reactive uptake coefficients for glyoxal and methylglyoxal uptake to aqueous aerosol particles and cloud droplets. The particle and droplet types considered were based on definitions in GEOS-Chem v11, but the approach is general. Liquid maritime and continental cloud droplets were considered. Aerosol types include sea salt (fine and coarse), with varying relative humidity and particle size, and sulfate/nitrate/ammonium as a function of relative humidity and particle composition. We take into account salting effects, aerosol thermodynamics, mass transfer, and irreversible reaction of the organic species with $\mathrm{OH}$ in the aqueous phase. The new recommended values for the reactive uptake coefficients in most cases are lower than those currently used in large-scale models, such as GEOS-Chem. We expect application of these parameterizations will result in improved representation of aqueous secondary organic aerosol formation in atmospheric chemistry models.
\end{abstract}

\section{Introduction}

The uptake and reaction of water-soluble volatile organic compounds (VOCs) in cloud droplets and aerosol liquid water is likely a significant source of secondary organic aerosol (SOA) material (Carlton et al., 2008; Fu et al., 2008, 2009; McNeill, 2015; McNeill et al., 2012). These processes may be referred to, collectively, as aqueous SOA (or aqSOA) formation.

Glyoxal (CHOCHO, GLYX) and methylglyoxal $\left(\mathrm{CH}_{3} \mathrm{C}(\mathrm{O}) \mathrm{CHO}, \mathrm{MGLY}\right)$ are both atmospherically abundant gas-phase oxidation products of multiple VOC precursors, including isoprene and toluene. Both GLYX and MGLY are water-soluble, GLYX more so than MGLY (Betterton and Hoffmann, 1988; Zhou and Mopper, 1990). Taking into account salting effects, the effective Henry's law constant for GLYX in aerosol water can be several orders of magnitude higher than that of MGLY, depending on the aerosol ionic content (Kampf et al., 2013; Waxman et al., 2015). As $\alpha$-dicarbonyl species, GLYX and MGLY exhibit similar aqueous-phase chemistry: they undergo reversible hydration and self-oligomerization (Ervens and Volkamer, 2010; Hastings et al., 2005; Sareen et al., 2010; Shapiro et al., 2009), they can be oxidized by aqueous-phase radicals to form organic acids or organosulfates (Carlton et al., 2007; Lim et al., 2013; Perri et al., 2010; Schaefer et al., 2012, 2015), and they can react with nitrogen-containing species to form brown carbon (De Haan et al., 2018; Lee et al., 2013; Maxut et al., 2015; Nozière et al., 2009; Powelson et al., 2014; Sareen et al., 2010; Schwier et al., 2010; Shapiro et al., 2009; Yu et al., 2011).

GLYX and MGLY received significant attention in the atmospheric chemistry modeling community (Carlton et al., 2008; Fu et al., 2008, 2009) following early experimental demonstrations of their potential significance as aqSOA precursors (Carlton et al., 2007; Hastings et al., 2005; Kroll et al., 2005; Loeffler et al., 2006). Fu and co-workers predicted that uptake of GLYX and MGLY to low-level clouds was a significant source of organic aerosol over North America, with MGLY producing more than 3 times more SOA than GLYX (Fu et al., 2009). Carlton et al. (2008) found that including in-cloud aqSOA production by GLYX in CMAQ improved agreement with aircraft observations. 
Since these initial studies, more information has become available regarding the gas-particle partitioning of glyoxal and methylglyoxal (Ip et al., 2009; Kampf et al., 2013; Waxman et al., 2015; Yu et al., 2011) and their chemical processing in the aqueous phase, allowing a refinement of their representation in models.

Here, we calculate reactive uptake coefficients for glyoxal and methylglyoxal for several cloud and aerosol types for application in large-scale atmospheric chemistry modeling. We take into account salting effects, aerosol thermodynamics, mass transfer considerations, and aqueous-phase chemical kinetics. We base our calculations on the cloud and aerosol types used in GEOS-Chem v11, so these recommendations can be applied directly to that model, but the approach is general.

\section{Methods and data}

Following Hanson et al. (1994), the reactive uptake coefficient, $\gamma$, is calculated according to

$$
\frac{1}{\gamma}=\frac{1}{\alpha}+\frac{\omega}{4 H^{*} R T \sqrt{k^{I} D_{\mathrm{aq}}}}\left(\frac{1}{\operatorname{cothq}-1 / q}\right),
$$

where $\alpha$ is the mass accommodation coefficient, $\omega$ is the gasphase thermal velocity of the organic species, $H^{*}$ is the effective Henry's law constant (Schwartz, 1986), $R$ is the universal gas constant, $T$ is temperature in Kelvin, $k^{I}$ is the first order aqueous loss rate, and $D_{\mathrm{aq}}$ is the aqueous-phase diffusion coefficient for the organic species. The particle radius, $R_{\mathrm{p}}$, and in-particle diffusion limitations are taken into account through the parameter $q=R_{\mathrm{p}} / l$, where $l$ is the diffusoreactive length:

$l=\left(\frac{D_{\mathrm{aq}}}{k^{I}}\right)^{1 / 2}$.

The aqueous-phase diffusion coefficient used for both GLYX and MGLY was $D_{\text {aq }}=10^{-9} \mathrm{~m}^{2} \mathrm{~s}^{-1}$. $D_{\text {aq }}$ does not vary much for small species, and this value is typical for small organics (Bird et al., 2006). The mass accommodation coefficient used was $\alpha=0.02$. This value of $\alpha$ is an estimate based on the assumption that $\alpha$ values for GLYX and MGLY are similar to that of formaldehyde uptake to water (Jayne et al., 1992). Following Eq. (1), the calculation is insensitive to within $10 \%$ for a $50 \%$ variation in $\alpha$ for values of $\gamma<10^{-3}$.

\subsection{Particle types and composition}

Although the approach described here is general, we applied it to the liquid cloud and aerosol particle types in GEOSChem v11. A complete listing can be found in the Supplement. Briefly, we considered marine and remote continental liquid cloud droplets, coarse and fine sea salt aerosol particles as a function of relative humidity (RH), and sulfate/nitrate/ammonium (SNA) aerosols as a function of $\mathrm{RH}$ and composition. Calculated results for $\gamma_{\mathrm{GLY}}$ and $\gamma_{\mathrm{MGLY}}$ as a function of $\mathrm{S}: \mathrm{A}, \mathrm{S}: \mathrm{N}$ and calculated $\mathrm{pH}$ are available in the Supplement. Sea salt aerosols are assumed to be composed of $100 \% \mathrm{NaCl}$. The Windows stand-alone executable for ISORROPIA-II (Fountoukis and Nenes, 2007) was used in forward mode to calculate the equilibrium inorganic ion composition of the aerosols, in order to calculate the Henry's constant. The temperature was held constant at $280 \mathrm{~K}$, and calculations were performed for each of the desired relative humidities $(99,95,90,80,70$, and $50 \%)$. Solid formation was suppressed (metastable mode). For the SNA aerosols, the amount of $\mathrm{NO}_{3}^{-}$was held constant at $2 \mu \mathrm{mol} \mathrm{m}{ }^{-3}$ air, while the $\mathrm{SO}_{4}^{-2}$ and $\mathrm{NH}_{3}$ amounts were each varied from 1 to $8 \mu \mathrm{mol} \mathrm{m}{ }^{-3}$.

\subsection{Aqueous-phase reaction}

The formulation in Eqs. (1) and (2) describes uptake due to irreversible aqueous-phase loss processes only. Based on our previous analysis of the system using the multiphase photochemical box model GAMMA, the dominant irreversible atmospheric aqueous-phase reactive process for GLYX and MGLY is the reaction with OH (McNeill, 2015; McNeill et al., 2012). This reaction is the initiation step for most radical-based chemistry of GLYX and MGLY in the atmospheric aqueous phase, including organic acid formation and organosulfate formation (McNeill et al., 2012; Perri et al., 2010). Other irreversible loss processes, such as imidazole formation, occur on much longer timescales (Teich et al., 2016; Yu et al., 2011). Therefore, the aqueous loss is represented by the pseudo-first-order rate constant for the reaction between the organic species of choice and $\mathrm{OH}$ (i.e., $\left.k^{I}=k_{\mathrm{OH}}[\mathrm{OH}]\right)$. Reversible reactive processes, e.g., spontaneous hydration and self-oligomerization of glyoxal and methylglyoxal, which substantially promote uptake of GLYX and MGLY to the aqueous phase, may be taken into account by the use of an effective Henry's law constant (McNeill et al., 2012). However, we note that the form of Eq. (1) implies no uptake (reversible or irreversible) in the absence of $\mathrm{OH}$.

Considerable uncertainty exists in the aqueous concentration of $\mathrm{OH}$ in cloud water and especially aerosol particles. In order to calculate $k^{I}$, we use $\mathrm{OH}$ concentrations for maritime and remote continental clouds and aerosols following Herrmann et al. (2010) (Table 1). They reported a range of [OH] for each scenario calculated using the CAPRAM 3.0 model. This $[\mathrm{OH}]$ range was used in the calculation of the uncertainty in $\gamma$.

\subsection{Calculating the Henry's constant}

The solubility of glyoxal and methylglyoxal in aqueous solutions depends on the salt content (Ip et al., 2009; Kampf et al., 2013; Waxman et al., 2015; Yu et al., 2011). Glyoxal becomes more soluble with increasing salt concentration (i.e., it exhibits "salting in"), whereas the opposite is true for methyl- 
Table 1. Mean values and range of in-particle hydroxyl radical concentrations, as reported by Herrmann et al. (2010).

\begin{tabular}{lrrr}
\hline Cloud/aerosol type & Mean $[\mathrm{OH}](\mathrm{M})$ & Max $[\mathrm{OH}](\mathrm{M})$ & Min $[\mathrm{OH}](\mathrm{M})$ \\
\hline Maritime aerosols & $10^{-13}$ & $3.3 \times 10^{-12}$ & $4.6 \times 10^{-15}$ \\
Remote aerosols & $3.0 \times 10^{-12}$ & $8 \times 10^{-12}$ & $5.5 \times 10^{-14}$ \\
Maritime clouds & $2.0 \times 10^{-12}$ & $5.3 \times 10^{-12}$ & $3.8 \times 10^{-14}$ \\
Remote clouds & $2.2 \times 10^{-14}$ & $6.9 \times 10^{-14}$ & $4.8 \times 10^{-15}$ \\
\hline
\end{tabular}

Table 2. Reaction and mass transfer parameters.

\begin{tabular}{lrrrrr}
\hline Species & $k_{\mathrm{OH}}\left(\mathrm{M}^{-1} \mathrm{~s}^{-1}\right)$ & $K_{\mathrm{H}, \mathrm{w}}\left(\mathrm{M} \mathrm{atm}^{-1}\right)$ & $K_{\mathrm{s}, \mathrm{NaCl}}\left(\mathrm{m}^{-1}\right)$ & $K_{\mathrm{s},\left(\mathrm{NH}_{4}\right) 2 \mathrm{SO}_{4}\left(\mathrm{~m}^{-1}\right)}$ & $K_{\mathrm{s}, \mathrm{NH}_{4} \mathrm{NO}_{3}}\left(\mathrm{~m}^{-1}\right)$ \\
\hline Glyoxal & $1.1 \times 10^{9 \mathrm{a}}$ & $3.5 \times 10^{5 \mathrm{c}}$ & $-0.10^{\mathrm{e}}$ & $-0.24^{\mathrm{d}}$ & $-0.07^{\mathrm{e}}$ \\
Methylglyoxal & $7 \times 10^{8 \mathrm{~b}}$ & $3.71 \times 10^{3 \mathrm{c}}$ & $0.06^{\mathrm{e}}$ & $0.16^{\mathrm{e}}$ & $0.075^{\mathrm{e}}$ \\
\hline
\end{tabular}

${ }^{\text {a }}$ Schaefer et al. (2015). ${ }^{\mathrm{b}}$ Schaefer et al. (2012). ${ }^{\mathrm{c}}$ Betterton and Hoffmann (1988). ${ }^{\mathrm{d}}$ Kampf et al. (2013). ${ }^{\mathrm{e}}$ Waxman et al. (2015).

glyoxal (it "salts out"). Therefore, the Henry's constants for glyoxal and methylglyoxal are a function of particle type and liquid water content (and therefore $\mathrm{RH}$ ).

The Henry's constants are calculated for sea salt aerosols following Waxman et al. (2015) using the following equation:

$\log \left(\frac{K_{\mathrm{H}, \mathrm{w}}}{K_{\mathrm{H}, \mathrm{NaCl}}}\right)=K_{\mathrm{s}, \mathrm{NaCl}} c_{\mathrm{NaCl}}$,

where $K_{\mathrm{H}, \mathrm{w}}$ is the Henry's constant for pure water, $K_{\mathrm{H}, \mathrm{NaCl}}$ is the Henry's constant for the salt-containing aerosol, $c_{\mathrm{NaCl}}$ is the $\mathrm{NaCl}$ concentration in molality as calculated using ISORROPIA-II, and $K_{\mathrm{s}, \mathrm{NaCl}}$ is the salting constant (Table 2). Note that the $K_{\mathrm{H}}$ values are effective Henry's constants, which account for hydration of the carbonyl species upon uptake. Waxman and co-workers showed that salting constants were additive for a mixed $\left(\mathrm{NH}_{4}\right)_{2} \mathrm{SO}_{4} / \mathrm{NH}_{4} \mathrm{NO}_{3}$ system, following

$$
\begin{aligned}
\log \left(\frac{K_{\mathrm{H}, \mathrm{w}}}{K_{\mathrm{H}, \mathrm{salt}}}\right) & =K_{\mathrm{s},\left(\mathrm{NH}_{4}\right)_{2} \mathrm{SO}_{4} c_{\left(\mathrm{NH}_{4}\right)_{2} \mathrm{SO}_{4}}} \\
& +K_{\mathrm{s}, \mathrm{NH}_{4} \mathrm{NO}_{3}} c_{\mathrm{NH}_{4} \mathrm{NO}_{3}},
\end{aligned}
$$

where $K_{\mathrm{H} \text {,salt }}$ is the Henry's constant for the salt mixture, $c_{\left(\mathrm{NH}_{4}\right) 2 \mathrm{SO}_{4}}$ and $c_{\mathrm{NH}_{4} \mathrm{NO}_{3}}$ are the concentrations in molality, and $K_{\mathrm{s},\left(\mathrm{NH}_{4}\right) 2 \mathrm{SO}_{4}}$ and $K_{\mathrm{s}, \mathrm{NH}_{4} \mathrm{NO}_{3}}$ are the salting constants. The sum of sulfate and bisulfate was used to calculate $c_{\left(\mathrm{NH}_{4}\right) 2 \mathrm{SO}_{4}}$.

For cloud droplets, $K_{\mathrm{H}, \mathrm{w}}$ is used due to the low ion concentrations in cloud water (Ervens, 2015; McNeill, 2015).

\subsection{Statistical analysis and parameter estimation}

The calculated reactive uptake coefficient, $\gamma$, for MGLY and GLYX and each particle type was parameterized as a function of RH via weighted least squares regression. Assuming that the errors in the reactive uptake coefficients are log- normally distributed, a covariance matrix for the model parameters was calculated based on the mean square errors of the data and the design matrix of the linear regression. The standard deviations of the model parameters were then determined from the diagonal of the covariance matrix (Aster et al., 2005). Student's $t$ tests were then performed on each model parameter for the hypothesis that the model parameter in question is equivalent to zero in order to assess the necessity of each parameter. The nonzero model parameter was kept for $t$ tests in which there was at least $98 \%$ confidence that the hypothesis of the model parameter being zero could be rejected.

\section{Results and discussion}

The reactive uptake coefficient, $\gamma$, was calculated for MGLY and GLYX as a function of [OH], RH, particle size, and in the case of SNA aerosol, particle composition. Calculated values of $\gamma$ varied over several orders of magnitude. In most cases these values are lower than those previously used to model reactive uptake of these species in large-scale models.

\subsection{Liquid cloud droplets}

The results for marine and remote continental cloud droplets are shown in Table 3, with the mean value and error bars given. The uncertainty reflects the uncertainty in $[\mathrm{OH}]$. $\gamma_{\text {MGLY }}$ is lower than $\gamma_{\text {GLYX }}$ by a factor of roughly 100 in each case, consistent with its lower $K_{\mathrm{H} \text {,w }}$ and $k_{\mathrm{OH}}$.

\subsection{Aerosols}

For aerosols, the reactive uptake coefficients were found to vary significantly with $\mathrm{RH}$ due to salting effects. Figure 1 shows calculated values of $\gamma_{\mathrm{GLYX}}$ for the three particle types as a function of RH. The range of uncertainty in the calculated values, indicated by the red shading, is due to the un- 

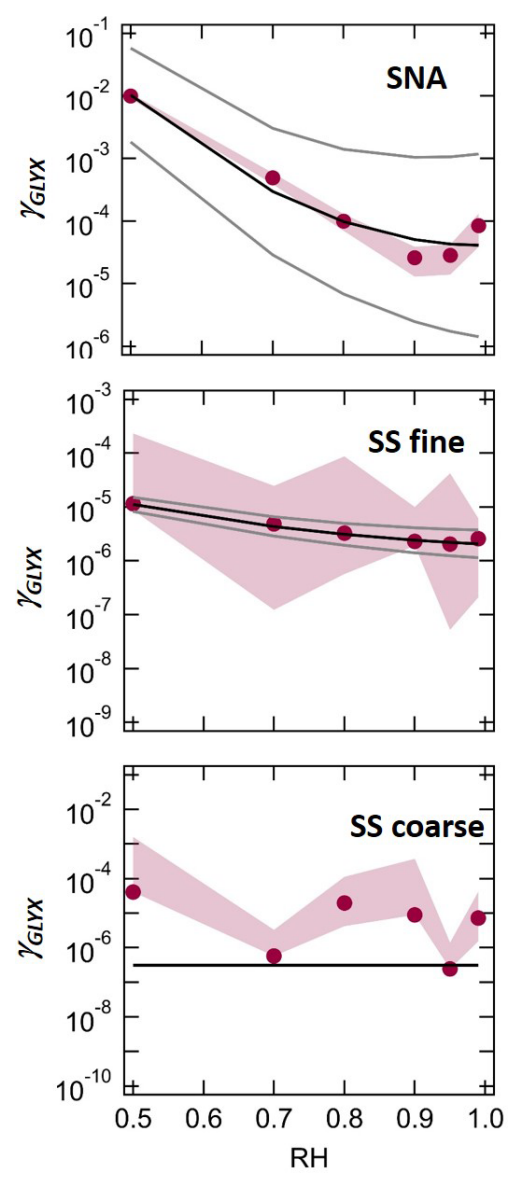

Figure 1. Calculated reactive uptake coefficients for uptake of glyoxal to sulfate/nitrate/ammonium (SNA) aerosols, and fine and coarse sea salt (SS) aerosols, as defined in GEOS-Chem v11. Red shading indicates the uncertainty in $\gamma_{\text {GLYX }}$. The black lines show the results of weighted least squares regression, with the confidence intervals in grey.

certainty in $[\mathrm{OH}]$ (Table 1), and in the case of SNA aerosols, variations due to the different aerosol compositions tested. The black lines indicate the weighted least squares fit to the data, and the grey lines indicate the confidence interval for the fit. The average values and the results of the least squares fits are summarized in Table 4.

$\gamma_{\text {GLYX }}$ decreases with increasing RH, due to salting in. Therefore, the maximum $\gamma_{\mathrm{GLYX}}\left(10^{-2}\right.$ for SNA, $\left.50 \% \mathrm{RH}\right)$ exceeds the dilute (cloud water) case. It also exceeds the general case used by $\mathrm{Fu}$ et al. (2008) $\left(\gamma_{\mathrm{GLYX}, \mathrm{Fu}}=2.9 \times 10^{-3}\right)$, which was based on the experimental observations of Liggio et al. (2005) for $\left(\mathrm{NH}_{4}\right)_{2} \mathrm{SO}_{4}$ aerosols at $55 \% \mathrm{RH}$. The parameterization presented in Table 4 yields $\gamma_{G L Y}=3.6 \times 10^{-3}$ at $55 \%$ RH.

In the case of coarse sea salt, in-particle diffusion limitations led to smaller $\gamma_{\text {GLYX }}$ at the mean $[\mathrm{OH}]$ than at the minimum $[\mathrm{OH}]$ for some $\mathrm{RH}$ values. The scatter in the calculated $\gamma_{\mathrm{GLYX}}$ led to a low-confidence result from the weighted least
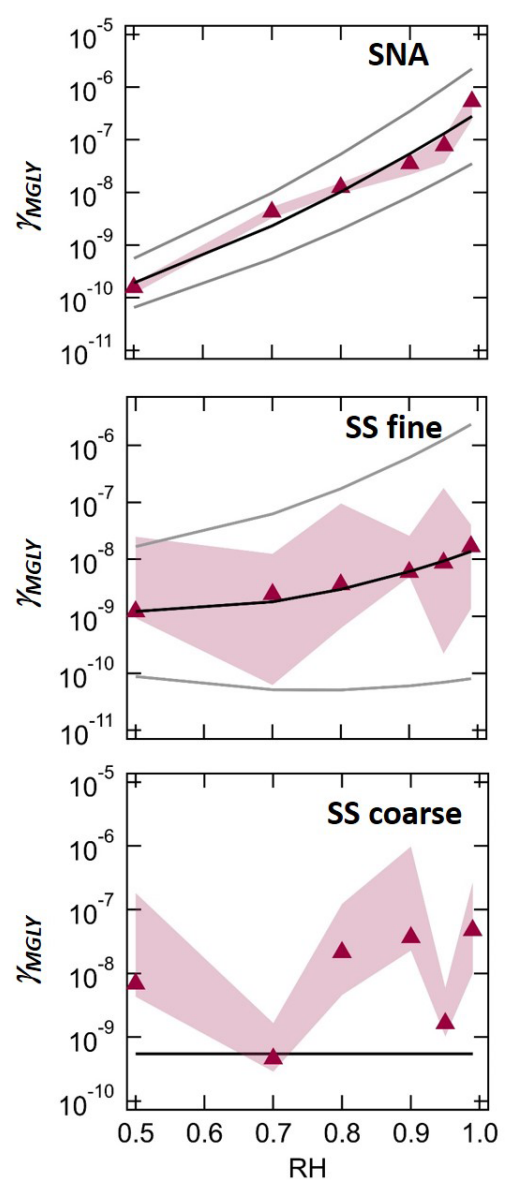

Figure 2. Calculated reactive uptake coefficients for uptake of methylglyoxal to sulfate/nitrate/ammonium (SNA) and sea salt (SS) aerosols. See text for details.

squares regression. For this reason, we recommend use of the error-weighted average $\gamma_{\text {GLYX }}$ value in lieu of a parameterization (Table 4).

Figure 2 shows calculated values of $\gamma_{\mathrm{MGLY}}$ as a function of RH. The average values and the results of the least squares fits are summarized in Table 5. In contrast to gly-

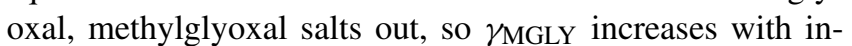
creasing RH. All calculated values $\left(10^{-10}<\gamma_{\text {MGLY }}<10^{-6}\right)$ are much smaller than the general case used by $\mathrm{Fu}$ et al. $(2008)\left(\gamma_{\text {MGLY,Fu }}=2.9 \times 10^{-3}\right)$. Those investigators had assumed that the reactive uptake coefficient for methylglyoxal would be equal to that for glyoxal as measured by Liggio et al. (2005).

Similar to the glyoxal case, the variability in $\gamma_{\text {MGLY for }}$ the coarse-mode sea salt aerosols due to in-particle diffusion limitations led to a low-confidence weighted least squares fit. The error-weighted average value is recommended.

For a given RH, $\gamma_{\text {GLYX }}$ and $\gamma_{\text {MGLY show weak, nonmono- }}$ tonic dependence on $\mathrm{S}: \mathrm{A}$ and $\mathrm{S}: \mathrm{N}$, with significant scatter (see the Supplement). Plotting $\gamma_{\mathrm{GLYX}}$ and $\gamma_{\mathrm{MGLY}}$ as a function of calculated aerosol $\mathrm{pH}$ shows a general positive trend, 
Table 3. Recommended $\gamma$ for liquid cloud droplets. Cloud types and size as defined in GEOS-Chem v11.

\begin{tabular}{lrrr}
\hline Cloud type & $R_{\text {eff }}(\mu \mathrm{m})$ & $\gamma_{\mathrm{GLYX}}$ & $\gamma_{\mathrm{MGLY}}$ \\
\hline Marine & 10 & $7.5 \times 10^{-4}\left(+0.001,-7.4 \times 10^{-4}\right)$ & $5.7 \times 10^{-6}\left(+9.4 \times 10^{-6},-5.6 \times 10^{-6}\right)$ \\
\hline Remote continental & 6 & $4.3 \times 10^{-6}\left(+9.2 \times 10^{-6},-3.4 \times 10^{-6}\right)$ & $3.2 \times 10^{-8}\left(+6.7 \times 10^{-8},-2.5 \times 10^{-8}\right)$ \\
\hline
\end{tabular}

Table 4. Summary of $\gamma_{\text {GLYX }}$ recommendations for aerosols. Aerosol types and specifications as defined in GEOS-Chem v11.

\begin{tabular}{lrr}
\hline Aerosol type & $\gamma_{\text {GLYX }}$ average value & $\begin{array}{r}\gamma_{\text {GLYX }} \text { parameterization } \\
\text { x: RH as fraction }\end{array}$ \\
\hline SNA & $1.0( \pm 0.1) \times 10^{-2}(\mathrm{RH}=50 \%)$ & $\gamma=\exp \left(a+b x+c x^{2}\right)$ \\
$4.9( \pm 1.0) \times 10^{-4}(\mathrm{RH}=70 \%)$ & $a=12.1( \pm 0.6)$ \\
$1.0( \pm 0.3) \times 10^{-4}(\mathrm{RH}=80 \%)$ & $b=-44.5( \pm 1.7)$ \\
$2.6( \pm 1.3) \times 10^{-5}(\mathrm{RH}=90 \%)$ & $c=22.3( \pm 1.1)$ \\
$2.8( \pm 1.4) \times 10^{-5}(\mathrm{RH}=95 \%)$ & $\mathrm{conf}=0.9997$ \\
& $8.5( \pm 4.6) \times 10^{-5}(\mathrm{RH}=99 \%)$ & $\gamma=\exp \left(a+b x+c x^{2}\right)$ \\
& $2.6 \times 10^{-6}\left(+0.04,-2.6 \times 10^{-6}\right)$ & $a=-7.5( \pm 0.1)$ \\
& & $b=-10.0( \pm 0.3)$ \\
& & $c=4.4( \pm 0.2)$ \\
& & conf $=0.9998$ \\
\hline Sea salt (fine) & & Average value recommended
\end{tabular}

Table 5. Summary of $\gamma_{\text {MGLY }}$ recommendations for aerosols.

\begin{tabular}{|c|c|c|}
\hline Aerosol type & $\gamma_{\text {MGLY average value }}$ & $\gamma_{\text {MGLY parameterization } x: \mathrm{RH} \text { as fraction }}$ \\
\hline SNA & $\begin{array}{r}1.6( \pm 0.4) \times 10^{-10}(\mathrm{RH}=50 \%) \\
4.3( \pm 1.0) \times 10^{-9}(\mathrm{RH}=70 \%) \\
1.3( \pm 0.3) \times 10^{-8}(\mathrm{RH}=80 \%) \\
3.5( \pm 1.5) \times 10^{-8}(\mathrm{RH}=90 \%) \\
7.7( \pm 4.1) \times 10^{-8}(\mathrm{RH}=95 \%) \\
5.3( \pm 2.9) \times 10^{-7}(\mathrm{RH}=99 \%)\end{array}$ & $\begin{array}{r}\gamma=\exp \left(a+b x+c x^{2}\right) \\
a=-25.7( \pm 0.4) \\
b=2.5( \pm 1.0) \\
c=8.3( \pm 0.7) \\
\text { conf }=0.9990\end{array}$ \\
\hline Sea salt (fine) & $6.5( \pm 1.3) \times 10^{-9}$ & $\begin{array}{r}\gamma=\exp \left(a+b x+c x^{2}\right) \\
a=-17.9( \pm 0.9) \\
b=-10.4( \pm 2.6) \\
c=10.3( \pm 1.7) \\
\operatorname{conf}=0.9909\end{array}$ \\
\hline Sea salt (coarse mode) & $5.5 \times 10^{-10}\left(+0.016,-5.5 \times 10^{-10}\right)$ & Average value recommended \\
\hline
\end{tabular}

with $\gamma$ increasing with increasing $\mathrm{pH}$ at a given $\mathrm{RH}$. These plots can be found in the Supplement along with a parameterization of the trend. We note that aerosol $\mathrm{pH}$ is not an independent parameter in our calculations, but rather a calculated output of ISORROPIA II as a function of input aerosol composition and RH. Furthermore, the mass transfer and reactive loss processes considered here are not explicitly $\mathrm{pH}$ dependent. Therefore, we interpret this apparent dependence on $\mathrm{pH}$ to be reflective of $\mathrm{pH}$ being a proxy for variations in solute concentration in the aerosol with varying aerosol liq- uid water content. All variations in $\gamma_{\text {GLYX }}$ and $\gamma_{\text {MGLY }}$ as a result of varying SNA aerosol composition or $\mathrm{pH}$ are incorporated in the error bars shown in the top panels of Figs. 1 and 2 , and therefore accounted for in the weighted least squares fits and the uncertainty ranges provided in the parameterizations in Tables 4 and 5. 


\section{Atmospheric implications}

We present revised recommendations for the reactive uptake coefficients for glyoxal and methylglyoxal for several cloud and aerosol types. The values we calculated under many conditions are lower than those currently used in largescale models such as GEOS-Chem, although we note that the parameterization presented in Table 4 under the experimental conditions of Liggio et al. (2005), $55 \%$ RH, yields $\gamma_{\mathrm{GLY}}=3.6 \times 10^{-3}$, which is within $24 \%$ of their experimental value $\left(2.9 \times 10^{-3}\right)$. We expect application of these parameterizations will result in a decrease in the calculated contribution of MGLY uptake to aqueous SOA formation and better representation of spatial variability in aqSOA formed from glyoxal. The reduced contribution of MGLY to aqueous SOA formation due to salting out is consistent with the calculations of Sareen et al. (2017).

Reactive uptake of glyoxal and methylglyoxal to other hygroscopic aerosols such as organic aerosols is possible, although given the importance of salting effects on this chemistry, and the low expected $[\mathrm{OH}]$ concentration in organic aerosols (McNeill, 2015), we expect the contribution of these processes to aqSOA formation to be minor.

This representation of aqueous SOA formation by GLYX and MGLY, with the treatment of Henry's constants described here, does not take into account the contribution of reversible uptake of GLYX, which could be a significant, although transient, source of aerosol mass under some conditions (McNeill et al., 2012; Woo and McNeill, 2015). The use of this parameterization together with simpleGAMMA (Woo and McNeill, 2015) would give representation of both aqSOA formation types by GLYX.

Data availability. Details of the GEOS-Chem v11 cloud and aerosol specifications, plots and parameterizations of reactive uptake coefficients as a function of aerosol composition and calculated aerosol $\mathrm{pH}$, and the MATLAB routine used for generating the data can be found in the Supplement.

\section{The Supplement related to this article is available online at https://doi.org/10.5194/acp-18-9823-2018-supplement.}

Author contributions. LAC performed calculations and assisted with the manuscript preparation. WGT assisted with the data analysis and manuscript preparation. VFM designed the research, performed calculations, analyzed the data, and wrote the manuscript.

Competing interests. The authors declare that they have no conflict of interest.
Acknowledgements. The authors acknowledge the NSF for funding this work (Award AGS-1546136). We are grateful to Tzung-May Fu for helpful discussions.

Edited by: Manabu Shiraiwa

Reviewed by: two anonymous referees

\section{References}

Aster, R. C., Thurber, C. H., and Borchers, B.: Parameter estimation and inverse problems, Elsevier Academic Press, 15-26, 2005.

Betterton, E. A. and Hoffmann, M. R.: Henry's Law Constants of Some Environmentally Important Aldehydes, Environ. Sci. Technol., 22, 1415-1418, 1988.

Bird, R. B., Stewart, W. E., and Lightfoot, E. N.: Transport Phenomena, Revised 2nd Edition, John Wiley \& Sons, Inc., 528-530, 2006.

Carlton, A. G., Turpin, B. J., Altieri, K. E., Seitzinger, S., Reff, A., Lim, H.-J., and Ervens, B.: Atmospheric oxalic acid and SOA production from glyoxal: Results of aqueous photooxidation experiments, Atmos. Environ., 41, 7588-7602, https://doi.org/10.1016/j.atmosenv.2007.05.035, 2007.

Carlton, A. G., Turpin, B. J., Altieri, K. E., Seitzinger, S. P., Mathur, R., Roselle, S. J. and Weber, R. J.: CMAQ Model Performance Enhanced When In-Cloud Secondary Organic Aerosol is Included: Comparisons of Organic Carbon Predictions with Measurements, Environ. Sci. Technol., 42, 87988802, https://doi.org/10.1021/es801192n, 2008.

De Haan, D. O., Tapavicza, E., Riva, M., Cui, T., Surratt, J. D., Smith, A. C., Jordan, M.-C., Nilakantan, S., Almodovar, M., Stewart, T. N., de Loera, A., De Haan, A. C., Cazaunau, M., Gratien, A., Pangui, E., and Doussin, J.F.: Nitrogen-Containing, Light-Absorbing Oligomers Produced in Aerosol Particles Exposed to Methylglyoxal, Photolysis, and Cloud Cycling, Environ. Sci. Technol., 52, 4061-4071, https://doi.org/10.1021/acs.est.7b06105, 2018.

Ervens, B.: Modeling the Processing of Aerosol and Trace Gases in Clouds and Fogs., Chem. Rev., 115, 4157-4198, https://doi.org/10.1021/cr5005887, 2015.

Ervens, B. and Volkamer, R.: Glyoxal processing by aerosol multiphase chemistry: towards a kinetic modeling framework of secondary organic aerosol formation in aqueous particles, Atmos. Chem. Phys., 10, 8219-8244, https://doi.org/10.5194/acp10-8219-2010, 2010.

Fountoukis, C. and Nenes, A.: ISORROPIA II: a computationally efficient thermodynamic equilibrium model for $\mathrm{K}^{+}$ $\mathrm{Ca}^{2+}-\mathrm{Mg}^{2+}-\mathrm{NH}_{4}^{+}-\mathrm{Na}^{+}-\mathrm{SO}_{4}^{2-}-\mathrm{NO}_{3}^{-}-\mathrm{Cl}^{-}-\mathrm{H}_{2} \mathrm{O}$ aero, Atmos. Chem. Phys., 7, 4639-4659, https://doi.org/10.5194/acp-7-46392007, 2007.

Fu, T.-M., Jacob, D. J., Wittrock, F., Burrows, J. P., Vrekoussis, M., and Henze, D. K.: Global budgets of atmospheric glyoxal and methylglyoxal, and implications for formation of secondary organic aerosols, J. Geophys. Res., 113, 1-17, https://doi.org/10.1029/2007JD009505, 2008.

Fu, T.-M., Jacob, D. J., and Heald, C. L.: Aqueous-phase reactive uptake of dicarbonyls as a source of organic aerosol over eastern North America, Atmos. Environ., 43, 1814-1822, https://doi.org/10.1016/j.atmosenv.2008.12.029, 2009. 
Hanson, D. R., Ravishankara, A. R., and Solomon, S.: Heterogeneous reactions in sulfuric acid aerosols: A framework for model calculations, J. Geophys. Res., 99, 3615, https://doi.org/10.1029/93JD02932, 1994.

Hastings, W. P., Koehler, C. A., Bailey, E. L., and De Haan, D. O.: Secondary Organic Aerosol Formation by Glyoxal Hydration and Oligomer Formation: Humidity Effects and Equilibrium Shifts during Analysis, Environ. Sci. Technol., 39, 8728-8735, https://doi.org/10.1021/es0504461, 2005.

Herrmann, H., Hoffmann, D., Schaefer, T., Bräuer, P., and Tilgner, A.: Tropospheric Aqueous-Phase Free-Radical Chemistry: Radical Sources, Spectra, Reaction Kinetics and Prediction Tools, Chem. Phys. Chem., 11, 3796-3822, https://doi.org/10.1002/cphc.201000533, 2010.

Ip, H. S. S., Huang, X. H. H., and Yu, J. Z.: Effective Henry's law constants of glyoxal, glyoxylic acid, and glycolic acid, Geophys. Res. Lett., 36, L01802, https://doi.org/10.1029/2008GL036212, 2009.

Jayne, J. T., Duan, S. X., Davidovits, P., Worsnop, D. R., Zahniser, M. S., and Kolb, C. E.: Uptake of gas-phase aldehydes by water surfaces, J. Phys. Chem., 96, 5452-5460, https://doi.org/10.1021/j100192a049, 1992.

Kampf, C. J., Waxman, E. M., Slowik, J. G., Dommen, J., Pfaffenberger, L., Praplan, A. P., Prévôt, A. S. H., Baltensperger, U., Hoffmann, T., and Volkamer, R.: Effective Henry's Law Partitioning and the Salting Constant of Glyoxal in Aerosols Containing Sulfate, Environ. Sci. Technol., 47, 4236-4244, https://doi.org/10.1021/es400083d, 2013.

Kroll, J. H., Ng, N. L., Murphy, S. M., Varutbangkul, V., Flagan, R. C., and Seinfeld, J. H.: Chamber studies of secondary organic aerosol growth by reactive uptake of simple carbonyl compounds, J. Geophys. Res., 110, 1-10, https://doi.org/10.1029/2005JD006004, 2005.

Lee, A. K. Y., Zhao, R., Li, R., Liggio, J., Li, S.-M., and Abbatt, J. P. D.: Formation of Light Absorbing Organo-Nitrogen Species from Evaporation of Droplets Containing Glyoxal and Ammonium Sulfate, Environ. Sci. Technol., 47, 12819-12826, https://doi.org/10.1021/es402687w, 2013.

Liggio, J., Li, S.-M., and McLaren, R.: Reactive uptake of glyoxal by particulate matter, J. Geophys. Res., 110, 1-13, https://doi.org/10.1029/2004JD005113, 2005.

Lim, Y. B., Tan, Y., and Turpin, B. J.: Chemical insights, explicit chemistry, and yields of secondary organic aerosol from $\mathrm{OH}$ radical oxidation of methylglyoxal and glyoxal in the aqueous phase, Atmos. Chem. Phys., 13, 8651-8667, https://doi.org/10.5194/acp-13-8651-2013, 2013.

Loeffler, K. W., Koehler, C. A., Paul, N. M., and De Haan, D. O.: Oligomer formation in evaporating aqueous glyoxal and methyl glyoxal solutions., Environ. Sci. Technol., 40, 6318-6323, 2006.

Maxut, A., Nozière, B., Fenet, B., and Mechakra, H.: Formation mechanisms and yields of small imidazoles from reactions of glyoxal with $\mathrm{NH}_{4}^{+}$in water at neutral $\mathrm{pH}$, Phys. Chem. Chem. Phys., 17, 20416-20424, https://doi.org/10.1039/C5CP03113C, 2015.

McNeill, V. F.: Aqueous Organic Chemistry in the Atmosphere: Sources and Chemical Processing of Organic Aerosols, Environ. Sci. Technol., 49, 1237-1244, https://doi.org/10.1021/es5043707, 2015.
McNeill, V. F., Woo, J. L., Kim, D. D., Schwier, A. N., Wannell, N. J., Sumner, A. J., and Barakat, J. M.: Aqueous-Phase Secondary Organic Aerosol and Organosulfate Formation in Atmospheric Aerosols: A Modeling Study, Environ. Sci. Technol., 46, 80758081, https://doi.org/10.1021/es3002986, 2012.

Nozière, B., Dziedzic, P., and Córdova, A.: Products and kinetics of the liquid-phase reaction of glyoxal catalyzed by ammonium ions $\left(\mathrm{NH}_{4}^{+}\right)$, J. Phys. Chem. A, 113, 231-237, https://doi.org/10.1021/jp8078293, 2009.

Perri, M. J., Lim, Y. B., Seitzinger, S. P., and Turpin, B. J.: Organosulfates from glycolaldehyde in aqueous aerosols and clouds: Laboratory studies, Atmos. Environ., 44, 2658-2664, https://doi.org/10.1016/j.atmosenv.2010.03.031, 2010.

Powelson, M. H., Espelien, B. M., Hawkins, L. N., Galloway, M. M., and De Haan, D. O.: Brown Carbon Formation by Aqueous-Phase Carbonyl Compound Reactions with Amines and Ammonium Sulfate, Environ. Sci. Technol., 48, 985-993, https://doi.org/10.1021/es4038325, 2014.

Sareen, N., Schwier, A. N. N., Shapiro, E. L. L., Mitroo, D., and McNeill, V. F. F.: Secondary organic material formed by methylglyoxal in aqueous aerosol mimics, Atmos. Chem. Phys., 10, $997-$ 1016, https://doi.org/10.5194/acp-10-997-2010, 2010.

Sareen, N., Waxman, E. M., Turpin, B. J., Volkamer, R., and Carlton, A. M. G.: Potential of aerosol liquid water to facilitate organic aerosol formation: assessing knowledge gaps about precursors and partitioning, Environ. Sci. Technol., 51, 3327-3335, https://doi.org/10.1021/acs.est.6b04540, 2017.

Schaefer, T., Schindelka, J., Hoffmann, D., and Herrmann, H.: Laboratory kinetic and mechanistic studies on the $\mathrm{OH}$-initiated oxidation of acetone in aqueous solution., J. Phys. Chem. A, 116, 6317-6326, https://doi.org/10.1021/jp2120753, 2012.

Schaefer, T., van Pinxteren, D., and Herrmann, H.: Multiphase chemistry of glyoxal: Revised kinetics of the alkyl radical reaction with molecular oxygen and the reaction of glyoxal with $\mathrm{OH}$, $\mathrm{NO}_{3}$ and $\mathrm{SO}_{4}(-)$ in aqueous solution, Environ. Sci. Technol., 49, 343-350, https://doi.org/10.1021/es505860s, 2015.

Schwartz, S. E.: Mass-transport considerations pertinent to aqueous phase reactions of gases in liquid-water clouds, in NATO ASI Series, Vol. G6, edited by: Jaeschke, W., 425-471, Springer-Verlag, Berlin Heidelberg, 1986.

Schwier, A. N., Sareen, N., Mitroo, D., Shapiro, E. L. E. L., and McNeill, V. F. F.: Glyoxal-methylglyoxal cross-reactions in secondary organic aerosol formation., Environ. Sci. Technol., 44, 6174-6182, https://doi.org/10.1021/es101225q, 2010.

Shapiro, E. L., Szprengiel, J., Sareen, N., Jen, C. N., Giordano, M. R., and McNeill, V. F.: Light-absorbing secondary organic material formed by glyoxal in aqueous aerosol mimics, Atmos. Chem. Phys., 9, 2289-2300, https://doi.org/10.5194/acp-9-2289-2009, 2009.

Teich, M., van Pinxteren, D., Kecorius, S., Wang, Z., and Herrmann, H.: First quantification of imidazoles in ambient aerosol particles: Potential photosensitizers, brown carbon constituents and hazardous components, Environ. Sci. Technol., 50, 1166-1173, https://doi.org/10.1021/acs.est.5b05474, 2016.

Waxman, E. M., Elm, J., Kurtén, T., Mikkelsen, K. V., Ziemann, P. J., and Volkamer, R.: Glyoxal and Methylglyoxal Setschenow Salting Constants in Sulfate, Nitrate, and Chloride Solutions: Measurements and Gibbs Energies, Environ. Sci. Technol., 49, 11500-11508, https://doi.org/10.1021/acs.est.5b02782, 2015. 
Woo, J. L. and McNeill, V. F.: simpleGAMMA v1.0 - a reduced model of secondary organic aerosol formation in the aqueous aerosol phase (aaSOA), Geosci. Model Dev., 8, 1821-1829, https://doi.org/10.5194/gmd-8-1821-2015, 2015.

Yu, G., Bayer, A. R., Galloway, M. M., Korshavn, K. J., Fry, C. G., and Keutsch, F. N.: Glyoxal in aqueous ammonium sulfate solutions: products, kinetics and hydration effects, Environ. Sci. Technol., 45, 6336-6342, https://doi.org/10.1021/es200989n, 2011.
Zhou, X. and Mopper, K.: Apparent Partition Coefficients of 15 Carbonyl Compounds between Air and Seawater and between Air and Freshwater; Implications for Air-Sea Exchange, Environ. Sci. Technol., 24, 1864-1869, 1990. 